\title{
Plant glyco-biotechnology on the way to synthetic biology
}

\section{Andreas Loos and Herta Steinkellner*}

Department of Applied Genetics and Cell Biology, University of Natural Resources and Life Sciences, Vienna, Austria

\section{Edited by:}

Els J. M. Van Damme, Ghent

University, Belgium

\section{Reviewed by:}

Beronda L. Montgomery, Michigan

State University, USA

Bjoern Usadel, RWTH Aachen

University, Germany

Thomas De Meyer, Vlaams Instituut

voor Biotechnologie, Belgium

\section{${ }^{*}$ Correspondence.}

Herta Steinkellner, Department of Applied Genetics and Cell Biology,

University of Natural Resources and Life Sciences, Muthgasse 18, 1190

Vienna, Austria

e-mail:herta.steinkellner@boku.ac.at
Plants are increasingly being used for the production of recombinant proteins. One reason is that plants are highly amenable to glycan engineering processes and allow the production of therapeutic proteins with increased efficacies due to optimized glycosylation profiles. Removal and insertion of glycosylation reactions by knock-out/knock-down approaches and introduction of glycosylation enzymes have paved the way for the humanization of the plant glycosylation pathway. The insertion of heterologous enzymes at exactly the right stage of the existing glycosylation pathway has turned out to be of utmost importance. To enable such precise targeting chimeric enzymes have been constructed. In this short review we will exemplify the importance of correct targeting of glycosyltransferases, we will give an overview of the targeting mechanism of glycosyltransferases, describe chimeric enzymes used in plant $\mathrm{N}$-glycosylation engineering and illustrate how plant glycoengineering builds on the tools offered by synthetic biology to construct such chimeric enzymes.

Keywords: glycoengineering, plant, glycosyltransferase, CTS, sub-Golgi targeting

\section{INTRODUCTION}

The medicinal use of proteins and blood products has a long history. Already in the 15th century ailing pope Innocent VIII was reportedly infused with blood from three healthy boys to give him back vigor and strength, however, with a fatal outcome for all four of them (Rivera et al., 2005). The first successful blood transfusion was made in 1665 between dogs (Felts, 2000) and it took over 150 years for the first successful transfusion between humans (Blundell, 1818). Proteins purified from animal or human tissues (growth hormones, insulin, clotting factors, or other blood components) have been used for medicinal purposes since the beginning of the 20th century (e.g., Eibl, 2008; Blizzard, 2012) and with the advent of recombinant protein production possibilities, many of those proteins are now produced recombinantly. The market for pharmaceutical proteins is assumed to currently amount to roughly 150-200 billion US\$, and develops strongly with growth rates of $\sim 10 \%$ and more (Walsh, 2010; Elvin et al., 2013; Aggarwal, 2014). Special drivers of this growth are antibodies and antibody related products, but also other types of proteins are selling well, like insulin, vaccines, erythropoietin, etc. (Aggarwal, 2014).

A current major concern in producing biopharmaceuticals is a special type of post-translation modification (PTM), namely $N$-glycosylation. This PTM is found on a large proportion of pharmaceutically relevant proteins (Walsh, 2010) and can influence protein characteristics like folding and assembly, solubility and charge, serum half-life, functionality, etc. (e.g., Varki, 1993; Roth et al., 2010; Solá and Griebenow, 2010). As different cell types attach different glycans, the characteristics of the $\mathrm{N}$-glycosylated protein can be strongly affected by the expression host - a fact that should be considered carefully when choosing the production system. For example, bacteria generally do not glycosylate proteins and yeasts attach larger glycan structures than mammals. Insect cells decorate proteins with paucimannosidic $N$-glycans which are normally not present in humans. Plants produce complex type $N$-glycans similar to humans, however, certain non-mammalian epitopes are attached and more complex human-type glycosylation cannot be produced (for reviews on typcial $\mathrm{N}$-glycosylation patterns and glycoengineering of different expression hosts see, e.g., Jacobs and Callewaert, 2009; Loos and Steinkellner, 2012). Another concern is glycan microheterogeneity, i.e., attachment of different $\mathrm{N}$-glycans to the same $\mathrm{N}$-glycosylation site, as homogeneously glycosylated products are required by the regulatory authorities. Thus, research has focused on modifying the glycosylation characteristics of a variety of expression systems to allow homogeneous, human-type $N$-glycosylation (Umana et al., 1999; Yamane-Ohnuki et al., 2004; Schuster et al., 2005; Cox et al., 2006; Li etal., 2006; Strasser etal., 2009; Pandhal and Wright, 2010; Meuris et al., 2014) and resulted in the production of proteins carrying modified glycans and often showing improved in vivo functions.

Plants have proven their capability regarding production speed, ease of scale up and to meet quality standards demanded by regulatory agencies for clinical applications (Gleba etal., 2014; Stoger et al., 2014). Also governmental agencies like the Defense Advanced Research Projects Agency [DARPA] (2012) have recognized the advantages of this technology for the quick manufacturing of vaccines, difficult to produce biopharmaceuticals, etc. This has led to massive investments in research, production facilities complying with current quality standards (Defense Advanced Research Projects Agency [DARPA], 2012; www.federalgrants.com, 2012; Stoger et al., 2014) and the first products on the market. Glucocerebrosidase, an enzyme to treat Gaucher's disease, has been approved by the FDA in 2013 as the first plant-produced, parenterally applied biopharmaceutical (Zimran et al., 2011; van Dussen et al., 2013). Additionally, several plant-made pharmaceuticals have received approval for clinical trials and other plant-produced products are 
already marketed as research/diagnostic reagent, medical device, cosmetic product etc. (recently reviewed by Gleba etal., 2014; Goodman, 2014; Stoger et al., 2014). Many of these proteins are glycosylated.

In this review we will discuss the approaches taken to engineer the $\mathrm{N}$-glycosylation pathway in Nicotiana benthamiana and put a strong focus on recently developed and applied semi-synthetic strategies using chimeric glycosyltransferases.

\section{PLANT GLYCOSYLATION}

In plants as in other eukaryotes, the endoplasmic reticulum (ER) and the Golgi apparatus play the central role in protein glycosylation and contain the majority of glycan modifying enzymes (reviewed by, e.g., Helenius and Aebi, 2001). While the ER and its glycan processing repertoire are largely conserved between phyla (and kingdoms), morphology and function of the Golgi differ to some extent (Loos and Steinkellner, 2012; Aebi, 2013). For example, a main function of the plant but not the mammalian Golgi is to provide large amounts of polysaccharides, a fundamental component of the cell wall (Oikawa et al., 2013). Early $\mathrm{N}$-glycosylation steps that take place in ER and cis-Golgi are virtually identical in higher eukaryotes, while further processing differs (recently reviewd by, e.g., Loos and Steinkellner, 2012; Bosch etal., 2013). This is mainly due to a drastically reduced repertoire of glycosylation enzymes in plants, where a small number of Golgi-located $N$-glycan processing enzymes gives rise to typically two different glycan structures (Castilho and Steinkellner, 2012). By comparison, over 2000 different $N$ glycans have been described on mammalian proteins which arise from several 100 enzymes in the secretory pathway (Campbell and Yarema, 2005; Ohtsubo and Marth, 2006; Varki, 2006). Notwithstanding these differences, the Golgi of higher eukaryotes shares a remarkably high degree of homology, especially with respect to organization, proteome, and $N$-glycosylation capabilities.

Plant proteins typically carry two major $\mathrm{N}$-glycans, complex GnGnXF and paucimannosidic MMXF (Strasser et al., 2004a, 2007a; for glycan nomenclature see http://www.proglycan.com/ upload/nomen_2007.pdf). These two glycans contain core $\alpha 1,3$ fucose and $\beta 1,2$-xylose which are plant-specific glyco-epitopes. They are not produced by mammalian cells and up to $50 \%$ of humans have been shown to carry substantial amounts of antibodies directed against these epitopes in their blood (Bardor et al., 2003). The abundantly present paucimannosidic structures (MMXF, truncated glycans lacking terminal GlcNAc residues; Dirnberger et al., 2001; Strasser et al., 2007a; Liebminger et al., 2011) are also a plant peculiarity, otherwise only found in insect cells (Altmann et al., 1999, 2001). In some cases plant proteins carry so-called Lewis A epitopes, terminally $\beta 1,3-$ galactosylated and $\alpha 1,4$-fucosylated structures (Fitchette-Laine etal., 1997; Strasser etal., 2007b). The abundance of this epitope differs strongly between species (Fitchette et al., 1999; Wilson et al., 2001) and organs (Strasser et al., 2007b), but seems low in Arabidopsis and Nicotiana (Fitchette etal., 1999; Strasser et al., 2007b, 2008; Matsuo and Matsumura, 2011). Noteworthy is also the absence of core $\alpha 1,6$-fucosylation in plants, a glycan residue present on the vast majority of proteins produced in mammalian cells. Removal of this residue from immunoglobulin G (IgG) glycans increases functional activities of antibodies due to a higher affinity to the antibody-dependent cell-mediated cytotoxicity (ADCC) inducing IgG receptor Fc $\gamma$ RIIIa (Shinkawa et al., 2003; Jefferis, 2009).

The limited glycosylation capacity of plants has turned out to be an advantage for the generation of proteins that need homogeneous glycosylation. For example, IgG antibodies produced in plants carry usually 1-2 different glycan structures (mainly GnGnXF) while the same antibodies produced in Chinese hamster ovary (CHO) cells bear 5-7 structures (Strasser et al., 2008, 2009). For some applications, like testing of functional activities, and according to the demands from regulatory agencies, homogeneous glycosylation is required.

Plants display a remarkable tolerance toward the manipulation of their intrinsic glycan biosynthetic pathways. Elimination of complex glycans, knock-out of plant-specific xylosyl- and fucosyltransferases (XT and FT) or reduction/overproduction of the Lewis A epitope did not lead to any obvious phenotype in Arabidopsis thaliana under standard growth conditions (Von Schaewen et al., 1993; Strasser et al., 2004b, 2007b). Also Lemna minor and N. benthamiana, one of the major plant-based protein production platforms, tolerate a variety of glycoengineering steps without obvious phenotypes or impact on development (Cox et al., 2006; Strasser et al., 2008; Nagels et al., 2011). Only few cases of sensitive reactions to glycosylation changes have been described (Fanata etal., 2013). This general tolerance for glycoengineering was a prerequisite for humanizing the plant $\mathrm{N}$-glycosylation pathway. A combination of knock-out/knockdown and knock-in approaches together with transient expression techniques has allowed the removal of potentially immunogenic residues, and the addition of new, human-type glycostructures. Modular, semi-synthetic constructs assembled on multi-gene vectors enable the efficient manipulation of the glycosylation pathway. These glycoengineering strategies are addressed below.

\section{PLANT GLYCOENGINEERING}

Engineering of plant glycans toward human structures requires two main types of modification: (i) plant-specific reactions have to be eliminated and (ii) reactions taking place in humans but not in plants have to be introduced. Reducing the unwanted plant-specific modifications, i.e., $\beta 1,2$-xylosylation and core $\alpha 1,3$-fucosylation, has initially been achieved by targeting the recombinant protein to the ER or co-overexpressing glycosylation enzymes competing for the same substrate (e.g., Palacpac etal., 1999; Bakker etal., 2006; Frey etal., 2009; Vézina et al., 2009; Karg et al., 2010; see below). However, as these approaches interfere with the execution of endogenous glycosylation processes and cause the attachment of oligomannosidic or incompletely processed and aberrant glycans they are only of limited use. RNAi approaches targeting the transcript of the unwanted glycosyltransferases or complete knock-outs by T-DNA insertion have proven more successful (Koprivova et al., 2004; Strasser et al., 2004b, 2008; Cox etal., 2006; Sourrouille et al., 2008; Shin et al., 2011; Parsons et al., 2012). Importantly, such plants produce human-type $\mathrm{GnGn}$ glycans, which serve as an 
acceptor substrate for further mammalian modifications and were thus important milestones in the engineering of the plant $\mathrm{N}$-glycosylation pathway toward the production of human-type structures.

Consequently, work over the past decade on the controlled expression of mammalian glycosyltransferases has established plant-based systems that synthesize a series of defined humantype glycan structures (Castilho et al., 2012; recently reviewed by Bosch etal., 2013). Recent studies demonstrate how even entire glycosylation-associated biosynthetic pathways can be introduced. Plants do not have the machinery to synthesize the sugar nucleotide precursor CMP-sialic acid (CMP- $N$-acetylneuraminic acid) necessary for sialylation. The simultaneous overexpression of six mammalian genes enabled the in planta generation of activated sialic acid, the transfer of the activated sugar nucleotide to the Golgi, the production of terminally galactosylated glycans and the transfer of sialic acid to these terminal galactoses (see Figures 1A-D; Castilho et al., 2008, 2010).
In planta sialylation of glycans thereby highlights some of the reasons why simple overexpression of a mammalian glycosyltransferase in plants has not always proven successful in generating human-type glycans: acceptor as well as donor substrates need to be present. For example, when Wee etal. (1998) expressed the human $\alpha 2,6$-sialyltransferase in Arabidopsis, activity of the enzyme could only be shown after applying donor and acceptor substrates in trans, as plants lack both. The achievements by Palacpac et al. (1999), Bakker et al. (2006) and others pointed out one more challenge, namely how delicate the glycosylation system is - coexpression of the human $\beta 1,4$-galactosyltransferase $(\beta 1,4-\mathrm{GalT})$ had led to the production of galactosylated, but also of unusual, hybrid-type glycans. The latter was due to activity of the galactosyltransferase at a suboptimal stage of the glycosylation pathway and interference with the endogenous glycosylation reactions (described in detail below). Similar findings were reported upon overexpression of $N$-acetylglucosaminyltransferase (GnT) III (Rouwendal et al.,
A

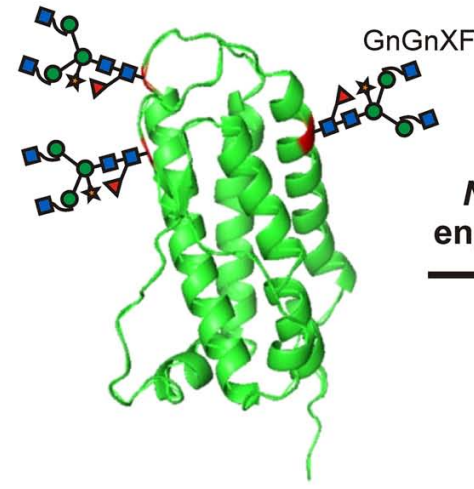

$\mathrm{N}$-glyco$\underset{\text { engineering }}{\longrightarrow}$

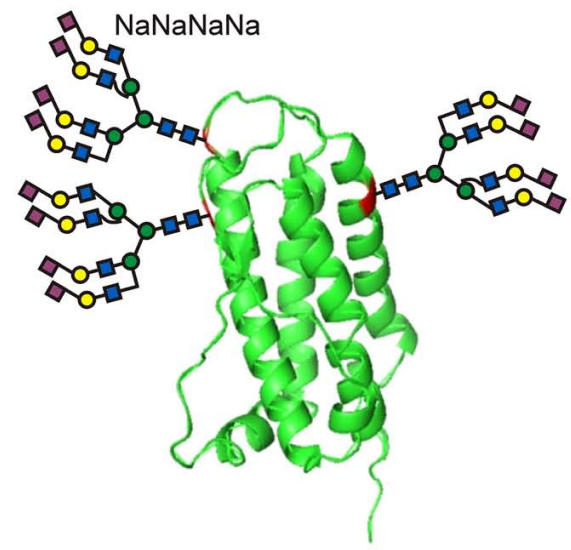

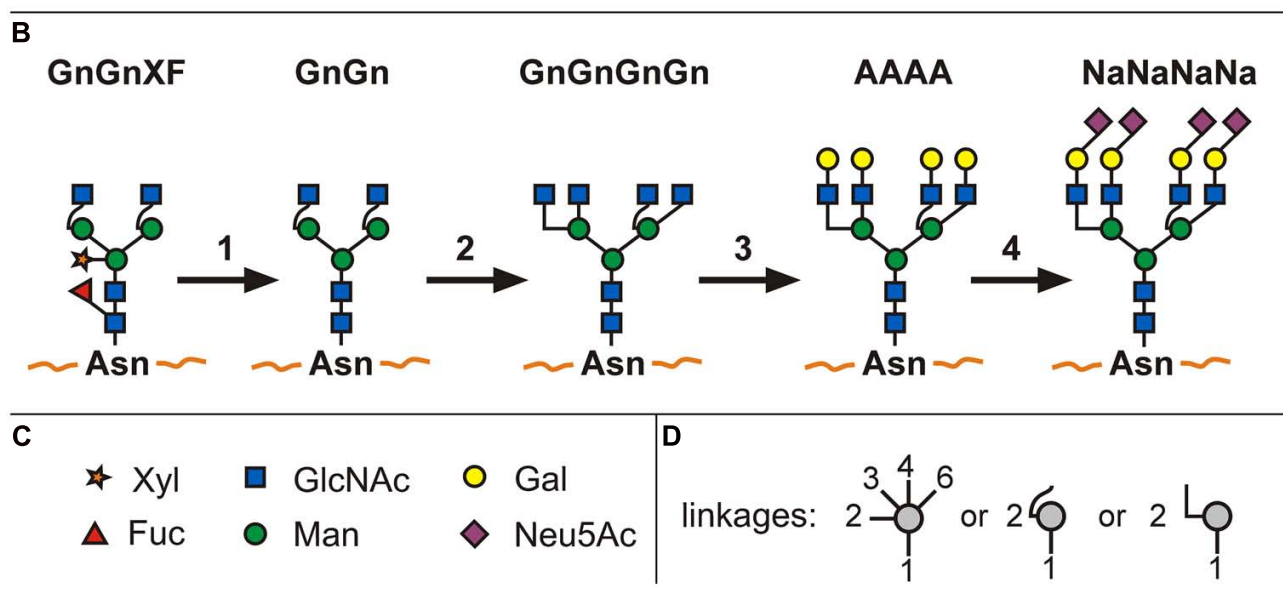

FIGURE 1 | $\mathbf{N}$-glycoengineering in plants to produce tetra-sialylated proteins. Schematic representation of an extensively glycoengineered plant-produced glycoprotein (erythropoietin; A). It represents the front of plant glycan engineering and illustrates, in short, the transformation of glycans present in Nicotiana benthamiana wild-type plants ( $G n G n X F)$ to finally obtain a glycosylation profile present on human serum EPO ( $\mathrm{NaNaNaNa).} \mathrm{For}$ such intensive $\mathrm{N}$-glycoengineering, a series of individual steps are necessary (B; 1): knock-out or knock-down of plant-specific $\beta 1,2-\mathrm{XT}$ and core $\alpha 1,3-\mathrm{FT}$, (2) introduction of GnTIV and GnTV responsible for branching, (3) introduction of $\beta 1,4-G a l T$, (4) introduction of sialyltransferase in combination with the biosynthetic pathway to produce activated sialic acid (not shown). Symbols for monosaccharides are given in (C), symbols depicting which monosaccharide atoms are involved in the linkage are given in (D). For detailed description see publications by Castilho etal. (2010, 2011, 2012, 2013). A more detailed explanation of $\mathrm{N}$-glycan nomenclature and graphical illustrations can be found at http://www.proglycan.com/upload/nomen_2007.pdf 
2007; Frey etal., 2009; Karg et al., 2010; Castilho et al., 2011; detailed description see below). These examples show that the final glycosylation profile of a co-expression approach depends on various factors, including the availability of (i) acceptor glycan and (ii) donor substrate as well as (iii) the correct subcellular targeting of the recombinant glycosyltransferase in order to avoid interference with the endogenous glycosylation machinery.

\section{TARGETING MECHANISM OF GLYCOSYLTRANSFERASES}

The glycosylation reactions within the Golgi are carried out in a sequential, stepwise manner, and one reaction can be the prerequisite for another one - or inhibit it. Therefore, the ordered sequential arrangement of enzymatic activities, i.e., the correct subcellular localization of the involved enzymes is of utmost importance. This tight regulation has consequences for the expression and targeting of heterologous glycosylation enzymes, as they need to fit precisely into the existing pathway. Fine-tuning the subcellular localization of heterologously expressed glycosylation enzymes requires vast knowledge of the underlying targeting mechanisms.

All known Golgi-resident $N$-glycosyltransferases are type II transmembrane proteins (reviewed by, e.g., Schoberer and Strasser, 2011). Their N-terminus is exposed to the cytoplasm, followed by a transmembrane domain, a stem, and the catalytic domain (see Figure 2). The cytoplasmic part, transmembrane domain, and stem are referred to as CTS region and are responsible

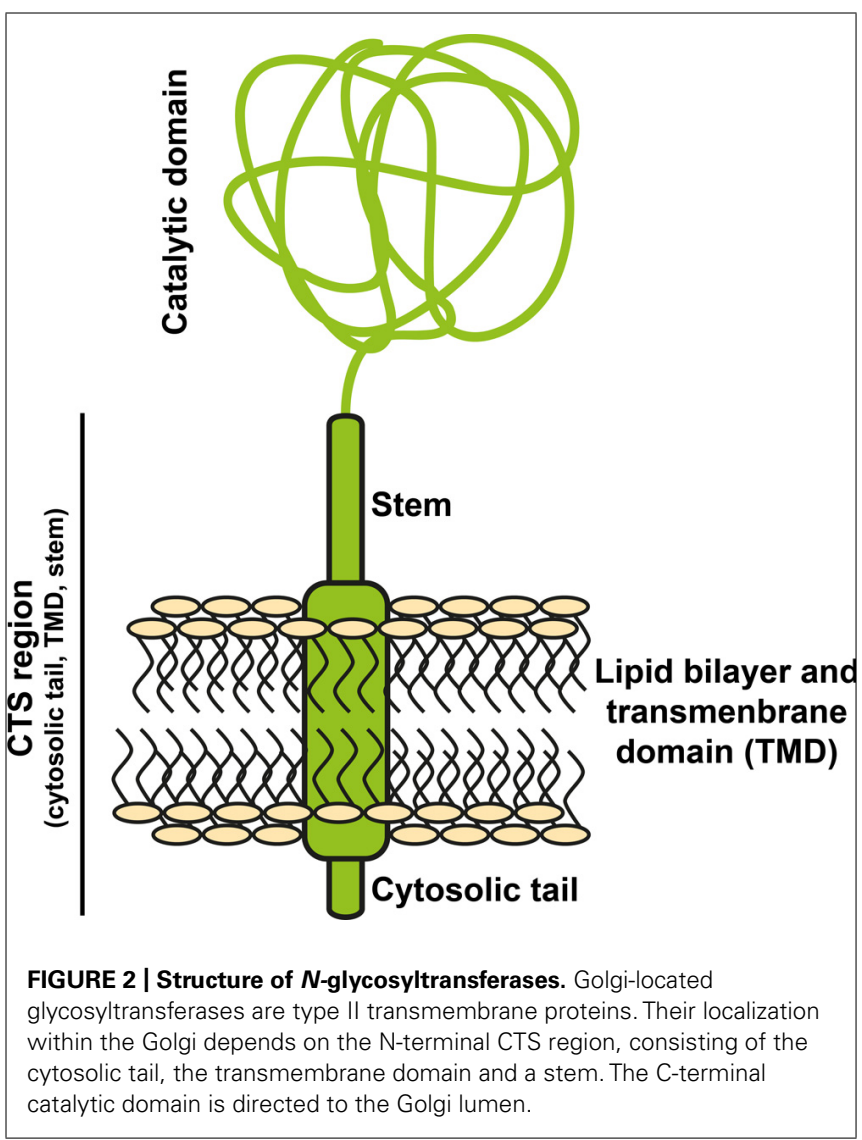

for targeting the enzyme to the correct compartment (Essl et al., 1999), and even sub-compartment. This was shown by different Golgi-localized glycosyltransferases not present within the same sub-compartment (Saint-Jore-Dupas et al., 2006; Schoberer et al., 2009, 2010).

Research activities to elucidate the targeting mechanism(s) of type II transmembrane proteins revealed a basic conservation of processes between plants and mammals (Schoberer et al., 2010). However, the question on how the fine-tuning of targeting works has not been answered definitively, but several factors have been identified. For example, the cytoplasmic tail influences ER export of the enzyme (Schoberer et al., 2009) and can change the final destination of a protein (Jiang and Rogers, 1998). In mammalian cells it has been shown to relocate the catalytic domain from one to another Golgi subcompartment (Uliana et al., 2006). This might be due to formation of homo- or heterodimers of the enzymes or interaction with other proteins (Schoberer et al., 2013). Also the length of the transmembrane domain might influence targeting (Pagny et al., 2003), as the membrane thickness of the Golgi changes from cis to trans. Finally, the composition of the lipid bilayer surrounding the enzyme might influence targeting, too (reviewed by Schoberer and Strasser, 2011). This makes the CTS regions of glycosyltransferases key regulators for precise sub-Golgi targeting. Theoretically, CTS domains from any eukaryotic organism may serve as a suitable targeting domain. Recent genome sequencing projects provided an abundance of such sequences that may be used for targeted sub-Golgi localization (Ohtsubo and Marth, 2006; Varki, 2006). Nevertheless, as the molecular mechanisms that lie behind this fine-tuning of targeting are not fully understood, it is not entirely predictable how CTS sequences actually perform when fused to the catalytic domain of another glycosyltransferase and expressed in a foreign cell. Thus, experimental testing is required. Also the prediction of the exact size of the individual glycosyltransferasedomains (cytosolic tail, transmembrane domain, stem, catalytic domain) is difficult and even though bioinformatics prediction technology has improved in recent years, different algorithms can lead to different results. Therefore, the reliability of the identification of the separate domains should be considered carefully.

\section{CHIMERIC GLYCOSYLTRANSFERASES USED FOR IN PLANTA GLYCOENGINEERING}

First steps to shift the plant $N$-glycosylation pattern from plantspecific $N$-glycans (i.e., GnGnXF, MMXF, etc.; see Figure 3A) toward the production of human-like structures were based on full-length mammalian glycosyltransferases. Expressing a human $\beta 1,4-G a l T$ in tobacco plants (Bakker et al., 2001) and tobacco BY2 cells (Palacpac et al., 1999) in fact resulted in galactosylated glycans, however, other oligosaccharides were produced as well. In BY2 cells, unusual and incompletely processed glycans lacking xylose and fucose (e.g., Man5A) were abundant (see Figure 3B), indicating interference of the heterologously expressed GalT with endogenous glycan processing enzymes like mannosidase II, GnTII and plant-specific $\beta 1,2$-xylosyltransferase and $\alpha 1,3-$ fucosyltransferase (XT and FT). In tobacco plants, xylosylated, and fucosylated GnGnXF remained the main oligosaccharide (see 


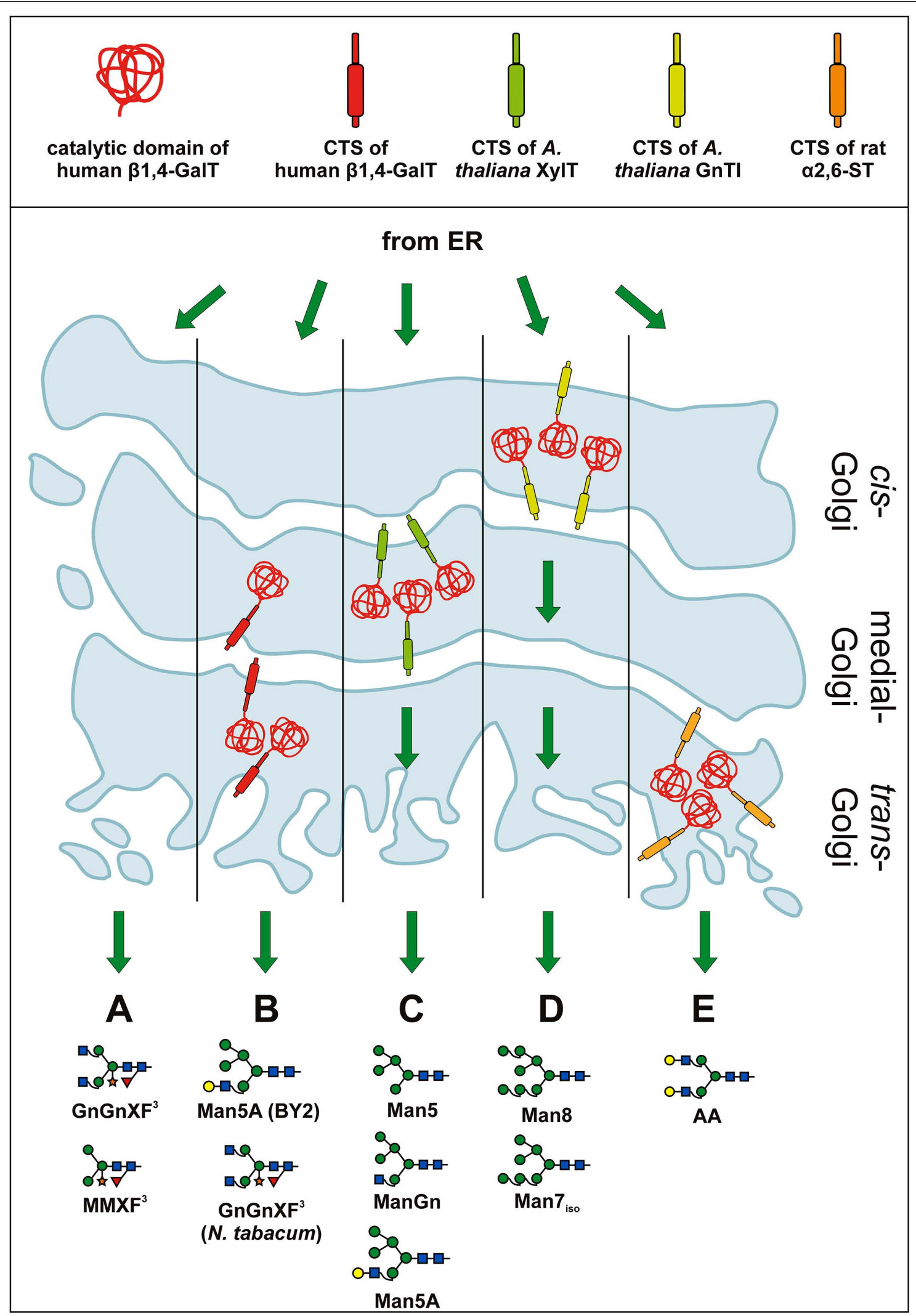

FIGURE 3 | Continued 


\section{FIGURE 3 | Continued \\ Expression of $\beta 1,4-G a l T$ and chimeric versions thereof in plants.}

Schematic presentation of various $\beta 1,4-$ GalT constructs expressed in plants and the consequences on the glycosylation profile of total and recombinantly expressed proteins. In the top panel $\beta 1,4-G a l T$ catalytic domain and various CTS regions are illustrated in different colors. The color code is used to better visualize various chimeric fusion constructs. The bottom panel shows a Golgi stack and the hypothetical localization of different $\beta 1,4-G a l T$ constructs. Green arrows indicate cargo flow from ER through the Golgi. Major glycan structures produced under the given conditions are shown. (A) Major glycoforms detected in wild-type plants (without the expression of $\beta 1,4-\mathrm{GalT}$ ) are complex $N$-glycans carrying xylose and fucose (i.e., GnGnXF, MMXF, etc.; e.g., Bakker et al., 2001).

(B) Expression of full-length human $\beta 1,4-G a l T$ in BY2 tobacco cells (Palacpac et al., 1999) and tobacco plants (Bakker et al., 2001) led to different results. In BY2 cells, mainly galactosylated, hybrid-type glycans (like Man5A) as well as oligomannosidic glycans were found (Palacpac et al., 1999). In tobacco plants (Bakker etal., 2001) GnGnXF remained the major glycoform and only small amounts of galactosylated glycans were found. These results indicate that $\beta 1,4-$ GalT acted in BY2 cells at an earlier stage of the glycosylation pathway than in tobacco plants, leading to interference with endogenous glycosylation reactions in cells, but not in plants. (C) Major glycoforms detected upon expression of a chimeric GalT, that carries the CTS region of

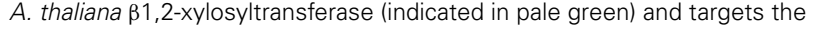
enzyme to a medial stage of the glycan processing pathway: Man5, ManGn, Man5A. A drastically reduced amount of xylosylated and fucosylated glycans was detected (Bakker et al., 2006). The results point to an early activity of the chimeric $\beta 1,4-G a l T$, most probably in medial Golgi stacks. (D) Targeting the GalT to an even earlier compartment by fusing it to the CTS of the cis-Golgi acting GnTI (indicated in yellow; Vézina etal., 2009) induced the production of nearly exclusively oligomannosidic structures. Only minute amounts of galactosylated, hybrid Man5A were present. (E) Upon expression in a XT/FT knock-down plant line of a chimeric GalT carrying the late-Golgi CTS of rat $\alpha 2,6$-sialyltransferase (indicated in orange) proteins carrying mainly galactosylated glycans (e.g., AA) were generated (Strasser et al., 2009). These results indicate that the ST-GalT fusion is indeed located in a late Golgi stack where final $N$-glycan processing takes place.

Figure 3B) and only minor amounts of galactosylated oligosaccharides like AAXF or GnAXF were found. This points to activity of the GalT at a later stage in tobacco plants, after completion of the endogenous glycosylation reactions. At this later stage, interference with the endogenous glycosylation reactions did not take place and therefore the amount of $\beta 1,2$-xylose and $\alpha 1,3$-fucose - residues unwanted on proteins needed for human applications - remained basically unchanged. In order to transfer the down-regulation effect observed in BY2 cells to tobacco plants and reduce/eliminate the two plant-specific glycan residues ( $\beta 1,2$-xylose and $\alpha 1,3$-fucose), a chimeric version of the human GalT was constructed that contained the CTS region of the $A$. thaliana $\beta 1$,2-xylosyltransferase (Bakker et al., 2006). The intention was to generate a chimeric enzyme that acts in the medial Golgi, simultaneously or prior to the endogenously present $\beta 1,2$ xylosyltransferase and core $\alpha 1,3$-fucosyltransferase (XT and FT). As $\beta 1,4$-galactosylated proteins are no longer substrates for XT and FT (Staudacher et al., 1995; Kajiura et al., 2012), the expression in tobacco plants led to the intended, drastic decrease in plant-specific glycans. However, the early activity of the $\beta 1,4-\mathrm{GalT}$ also led to the inhibition of other enzymes - like mannosidase II and GnTII - and thus to the generation of substantial amounts of unusual, incompletely processed glycans (oligomannosidic glycans, Man5A, etc.; see Figure 3C). Altogether, the glycan profile was similar to the profile of BY2 cells expressing the full-length human $\beta 1$ 1,4-GalT (Palacpac et al., 1999). This indicates that the chimeric construct in tobacco plants and the full-length, human GalT in BY2 cells show activity at a comparable stage of the glycosylation pathway.

Targeting the human $\beta 1,4-G a l T$ to an even earlier compartment (ER/cis-Golgi) by fusion with the CTS region of the $A$. thaliana GnTI further increased the amount of oligomannosidic glycans (Vézina et al., 2009; see Figure 3D). Galactosylated oligosaccharides were hardly found, indicating increased interference with the glycosylation machinery and the secretory pathway.

With the advent of XT/FT knock-down or knock-out lines (Koprivova et al., 2004; Cox et al., 2006; Schähs et al., 2007; Strasser etal., 2008; Shin etal., 2011) a more elegant way to prevent plant-specific glycosylation had been established and the aim of co-expressing human GalT in plants shifted from "interfering with endogenous reactions" to "generating homogeneously galactosylated, human-type glycans." This was achieved by a rationally designed construct targeting the GalT to a late Golgi compartment. Fusions of the catalytic GalT domain to the CTS region of $\alpha 2,6$-sialyltransferase, an enzyme acting in the final steps of the mammalian glycosylation pathway, indeed resulted in the generation of human-type, mono- and di-galactosylated glycans in XT/FT knock-down plants (Strasser et al., 2009; see Figure 3E). This was an important step for the in planta generation of proteins carrying fully human glycans.

This semi-synthetic approach was applied to GnTs to further explore the consequences of generating hybrid constructs carrying foreign CTS regions. One of the GnTs, $\beta 1,4$-mannosyl- $\beta 1,4-N$ acetylglucosaminyltransferase (GnTIII), catalyzes the formation of so-called bisected glycans (Carver et al., 1981; Narasimhan, 1982), a modification frequently found on human proteins but not present in plants (Rouwendal et al., 2007). Importantly, bisected - as well as the previously mentioned $\beta 1,4-$ galactosylated glycans - cannot be modified with plant-specific xylose or fucose residues (Rouwendal et al., 2007). In order to produce such bisected glycans and thus prevent the addition of plant-specific glyco-epitopes, fully human GnTIII and a hybrid construct (the catalytic domain was fused to the CTS region of $A$. thaliana $\alpha$-mannosidase II) were expressed in tobacco plants and BY-2 tobacco cells. The chimeric constructs led to a stronger decrease in plant-specific glyco-epitopes most probably due to targeting to an early/medial Golgi subcompartment (Rouwendal etal., 2007; Frey etal., 2009; Karg et al., 2010). However, targeting of GnTIII to an early compartment not only inhibited unwanted reactions but also led to the generation of non-standard, mainly hybrid-type glycans. Transiently expressing a series of GnTIII-constructs containing different CTS regions (A. thaliana Golgi mannosidase II, A. thaliana core $\alpha 1,3-$ fucosyltransferase, $A$. thaliana $\beta 1,2$-xyloslytransferase, and rat $\alpha 2,6$-sialyltransferase) in XT/FT knock-down $N$. benthamiana plants identified late targeting sequences as preferential for the production of naturally occurring, bisected $N$-glycans (Castilho et al., 2011).

In a similar approach, enzymes responsible for branched glycans (i.e., tri- and tetraantennary glycans; human $\alpha 1,3$-mannosyl$\beta 1,4-N$-acetylglucosaminyltransferase IVa (GnTIV) and human 
$\alpha 1,6$-mannosyl- $\beta 1,6-N$-acetylglucosaminyltransferase V (GnTV)) were tested with different CTS regions (endogenous CTS region, rat $\alpha 2,6$-sialyltransferase, $A$. thaliana core $\alpha 1,3$-fucosyltransferase, A. thaliana $\beta 1$,2-xyloslytransferase; Castilho et al., 2011; Nagels et al., 2011, 2012a,b). The fusions with the medial Golgi-targeting CTS region of, e.g., FT allowed the generation of a high degree of branched glycans on co-expressed reporter proteins, whereas the endogenous CTS and the late Golgi CTS from $\alpha 2,6$ sialyltransferase did not lead to substantial amounts of branched glycans.

Collectively these results demonstrate that it is not sufficient to "simply" introduce a foreign glycosylation enzyme into a plant to obtain a desired glycan structure. Instead, the successful production of proteins with human-type $N$-glycosylation in plants harbors a large number of challenges and requires knowledge of glycosylation pathways, enzyme specificities and related topics, like subcellular protein transport. Semi-synthetic approaches serve as useful tools to approach these challenges.

\section{FURTHER CHALLENGES}

In recent years, a variety of expression hosts were glyco-engineered (recently reviewed by, e.g., Jacobs and Callewaert, 2009; Loos and Steinkellner, 2012) and the first products with enhanced properties in animal studies have reached the clinic (Ratner, 2014). Plants, with their similar-to-human yet more simple $N$-glycosylation machinery and their amenability to glyco-engineering have been on the forefront of this development. Despite substantial achievements, the advantages of this system have been used only in a few in vivo studies (Bendandi et al., 2010; Forthal et al., 2010; Zeitlin et al., 2011, 2013; Hiatt et al., 2014). So far only one plantproduced product has reached the market, i.e., glucocerebrosidase to treat Gaucher's disease. This protein carries terminal mannose residues, a glycosylation form that confers enhanced efficacies (Grabowski et al., 2014). Another plant-produced glyco-optimized protein drug has recently been used to treat patients: ZMapp, an experimental mAb cocktail against Ebola virus was given to several individuals during the ongoing Ebola epidemic (critically reviewed by Goodman, 2014). These antibodies had not yet gone through clinical studies but due to the dire predictions of Ebola virus infection and lack of other treatment options its application had been approved by regulatory authorities in several countries.

With the appearance of efficient, transient expression methods, the rapid, scalable and cost-effective production of high-value recombinant proteins became possible (Gleba et al., 2014). However, to realize the full potential of plant biotechnology, advanced, stably glyco-engineered plant strains in combination with semisynthetic approaches will be needed. Versatile, modular expression vectors like MoClo (Weber et al., 2011) and GoldenBraid (SarrionPerdigones et al., 2013) allow efficient shuffling of domains and will certainly speed up the generation of constructs. Quick assembly of multi-gene vectors also simplifies the remodeling of glycosylation pathways as recently demonstrated (Schneider et al., 2014). Moreover, new technologies for genome editing, like CRISPR and TALENs (Lozano-Juste and Cutler, 2014) allow efficient elimination of genes and facilitate metabolic engineering and reprogramming of biosynthetic processes. These developments in combination with computer modeling and simulation approaches that predict protein-glycan interactions will accelerate the development of drugs with optimized and even new functions. In sum, the currently available gene expression systems and the new tools offered by synthetic biology create an ideal environment for establishing a plant-based biomanufacturing platform that can compete with or even surpass current industry standards.

\section{ACKNOWLEDGMENTS}

We thank Jürgen Retzer for assistance with figure preparation. This work was supported by grants from the Austrian Research Promotion Agency (FFG) Laura Bassi Centres of Expertise (Number 822757, to Herta Steinkellner) and from the Austrian Science Fund (FWF; Grant Number L575-B13, to Herta Steinkellner).

\section{REFERENCES}

Aebi, M. (2013). N-linked protein glycosylation in the ER. Biochim. Biophys. Acta 1833, 2430-2437. doi: 10.1016/j.bbamcr.2013.04.001

Aggarwal, R. S. (2014). What's fueling the biotech engine-2012 to 2013. Nat. Biotechnol. 32, 32-39. doi: 10.1038/nbt.2794

Altmann, F., Fabini, G., Ahorn, H., and Wilson, I. B. (2001). Genetic model organisms in the study of $N$-glycans. Biochimie 83, 703-712. doi: 10.1016/S03009084(01)01297-4

Altmann, F., Staudacher, E., Wilson, I. B., and Marz, L. (1999). Insect cells as hosts for the expression of recombinant glycoproteins. Glycoconj. J. 16, 109-123. doi: 10.1023/A:1026488408951

Bakker, H., Bardor, M., Molthoff, J. W., Gomord, V., Elbers, I., Stevens, L. H., et al. (2001). Galactose-extended glycans of antibodies produced by transgenic plants. Proc. Natl. Acad. Sci. U.S.A. 98, 2899-2904. doi: 10.1073/pnas.0314 19998

Bakker, H., Rouwendal, G. J., Karnoup, A. S., Florack, D. E., Stoopen, G. M., Helsper, J. P., et al. (2006). An antibody produced in tobacco expressing a hybrid beta-1,4galactosyltransferase is essentially devoid of plant carbohydrate epitopes. Proc. Natl. Acad. Sci. U.S.A. 103, 7577-7582. doi: 10.1073/pnas.0600879103

Bardor, M., Faveeuw, C., Fitchette, A. C., Gilbert, D., Galas, L., Trottein, F., et al. (2003). Immunoreactivity in mammals of two typical plant glycoepitopes, core alpha(1,3)-fucose and core xylose. Glycobiology 13, 427-434. doi: $10.1093 /$ glycob/cwg024

Bendandi, M., Marillonnet, S., Kandzia, R., Thieme, F., Nickstadt, A., Herz, S., et al. (2010). Rapid, high-yield production in plants of individualized idiotype vaccines for non-Hodgkin's lymphoma. Ann. Oncol. 21, 2420-2427. doi: 10.1093/annonc/mdq256

Blizzard, R. M. (2012). History of growth hormone therapy. Indian J. Pediatr. 79, 87-91. doi: 10.1007/s12098-011-0609-4

Blundell, J. (1818). Experiments on the transfusion of blood by the syringe. Med. Chir. Trans. 9, 56-92.

Bosch, D., Castilho, A., Loos, A., Schots, A., and Steinkellner, H. (2013). $\mathrm{N}$-Glycosylation of plant-produced recombinant proteins. Curr. Pharm. Des. 19, 5503-5512. doi: 10.2174/1381612811319310006

Campbell, C. T., and Yarema, K. J. (2005). Large-scale approaches for glycobiology. Genome Biol. 6:236. doi: 10.1186/gb-2005-6-11-236

Carver, J. P., Grey, A. A., Winnik, F. M., Hakimi, J., Ceccarini, C., and Atkinson, P. H. (1981). Determination of the structure of four glycopeptides from hen ovalbumin using 360-MHz proton magnetic resonance spectroscopy. Biochemistry 20, 66006606. doi: 10.1021/bi00526a013

Castilho, A., Gattinger, P., Grass, J., Jez, J., Pabst, M., Altmann, F., et al. (2011). $\mathrm{N}$-glycosylation engineering of plants for the biosynthesis of glycoproteins with bisected and branched complex $N$-glycans. Glycobiology 21, 813-823. doi: $10.1093 /$ glycob/cwr009

Castilho, A., Neumann, L., Daskalova, S., Mason, H. S., Steinkellner, H., Altmann, F., et al. (2012). Engineering of sialylated mucin-type $O$-glycosylation in plants. J. Biol. Chem. 287, 36518-36526. doi: 10.1074/jbc.M112.402685

Castilho, A., Neumann, L., Gattinger, P., Strasser, R., Vorauer-Uhl, K., Sterovsky, T., et al. (2013). Generation of biologically active multi-sialylated recombinant human EPOFc in plants. PLOS ONE 8:e54836. doi: 10.1371/journal.pone.00 54836 
Castilho, A., Pabst, M., Leonard, R., Veit, C., Altmann, F., Mach, L., et al. (2008). Construction of a functional CMP-sialic acid biosynthesis pathway in Arabidopsis. Plant Physiol. 147, 331-339. doi: 10.1104/pp.108.117572

Castilho, A., and Steinkellner, H. (2012). Glyco-engineering in plants to produce human-like $N$-glycan structures. Biotechnol. J. 7, 1088-1098. doi: 10.1002/biot.201200032

Castilho, A., Strasser, R., Stadlmann, J., Grass, J., Jez, J., Gattinger, P., et al. (2010). In planta protein sialylation through overexpression of the respective mammalian pathway. J. Biol. Chem. 285, 15923-15930. doi: 10.1074/jbc.M109.088401

Cox, K. M., Sterling, J. D., Regan, J. T., Gasdaska, J. R., Frantz, K. K., Peele, C. G., et al. (2006). Glycan optimization of a human monoclonal antibody in the aquatic plant Lemna minor. Nat. Biotechnol. 24, 1591-1597. doi: 10.1038/nbt1260

Defense Advanced Research Projects Agency [DARPA]. (2012). DARPA Produces Over 10 Million Doses of H1N1 Vaccine Candidate in One Month. Available at: http://www.darpa.mil/NewsEvents/Releases/2012/07/25.aspx (accessed July 7, 2014).

Dirnberger, D., Steinkellner, H., Abdennebi, L., Remy, J. J., and Van De Wiel, D. (2001). Secretion of biologically active glycoforms of bovine follicle stimulating hormone in plants. Eur. J. Biochem. 268, 4570-4579. doi 10.1046/j.1432-1327.2001.02384.x

Eibl, M. M. (2008). History of immunoglobulin replacement. Immunol. Allergy Clin. North Am. 28, 737-764. doi: 10.1016/j.iac.2008.06.004

Elvin, J. G., Couston, R. G., and Van Der Walle, C. F. (2013). Therapeutic antibodies: market considerations, disease targets and bioprocessing. Int. J. Pharm. 440 83-98. doi: 10.1016/j.ijpharm.2011.12.039

Essl, D., Dirnberger, D., Gomord, V., Strasser, R., Faye, L., Glossl, J., et al. (1999) The N-terminal 77 amino acids from tobacco $N$-acetylglucosaminyltransferase I are sufficient to retain a reporter protein in the Golgi apparatus of Nicotiana benthamiana cells. FEBS Lett. 453, 169-173. doi: 10.1016/S0014-5793(99) 00712-7

Fanata, W. I. D., Lee, K. H., Son, B. H., Yoo, J. Y., Harmoko, R., Ko, K. S., et al. (2013). $N$-glycan maturation is crucial for cytokinin-mediated development and cellulose synthesis in Oryza sativa. Plant J. 73, 966-979. doi: 10.1111/tpj.12087

Felts, J. H. (2000). Richard lower: anatomist and physiologist. Ann. Intern. Med. 132, 420-423. doi: 10.7326/0003-4819-132-5-200003070-00023

Fitchette, A. C., Cabanes-Macheteau, M., Marvin, L., Martin, B., Satiat-Jeunemaitre, B., Gomord, V., et al. (1999). Biosynthesis and immunolocalization of Lewis a-containing $\mathrm{N}$-glycans in the plant cell. Plant Physiol. 121, 333-344. doi: 10.1104/pp.121.2.333

Fitchette-Laine, A. C., Gomord, V., Cabanes, M., Michalski, J. C., Saint Macary, M., Foucher, B., et al. (1997). N-glycans harboring the Lewis a epitope are expressed at the surface of plant cells. Plant J. 12, 1411-1417. doi: 10.1046/j.1365-313x.1997.12061411.x

Forthal, D. N., Gach, J. S., Landucci, G., Jez, J., Strasser, R., Kunert, R., et al. (2010). Fc-glycosylation influences Fc $\gamma$ receptor binding and cell-mediated antiHIV activity of monoclonal antibody 2G12. J. Immunol. 185, 6876-6882. doi 10.4049/jimmunol.1002600

Frey, A. D., Karg, S. R., and Kallio, P. T. (2009). Expression of rat beta(1,4)$\mathrm{N}$-acetylglucosaminyltransferase III in Nicotiana tabacum remodels the plantspecific N-glycosylation. Plant Biotechnol. J. 7, 33-48. doi: 10.1111/j.14677652.2008.00370.x

Gleba, Y. Y., Tuse, D., and Giritch, A. (2014). Plant viral vectors for delivery by Agrobacterium. Curr. Top. Microbiol. Immunol. 375, 155-192. doi 10.1007/82_2013_352

Goodman, J. L. (2014). Studying "Secret Serums" - toward safe, effective ebola treatments. N. Engl. J. Med. 371, 1086-1089. doi: 10.1056/NEJMp1409817

Grabowski, G. A., Golembo, M., and Shaaltiel, Y. (2014). Taliglucerase alfa: an enzyme replacement therapy using plant cell expression technology. Mol. Genet. Metab. 112, 1-8. doi: 10.1016/j.ymgme.2014.02.011

Helenius, A., and Aebi, M. (2001). Intracellular functions of $N$-linked glycans. Science 291, 2364-2369. doi: 10.1126/science.291.5512.2364

Hiatt, A., Bohorova, N., Bohorov, O., Goodman, C., Kim, D., Pauly, M. H., et al. (2014). Glycan variants of a respiratory syncytial virus antibody with enhanced effector function and in vivo efficacy. Proc. Natl. Acad. Sci. U.S.A. 111, 5992-5997. doi: $10.1073 /$ pnas.1402458111

Jacobs, P. P., and Callewaert, N. (2009). N-glycosylation engineering of biopharmaceutical expression systems. Curr. Mol. Med. 9, 774-800. doi: $10.2174 / 156652409789105552$
Jefferis, R. (2009). Glycosylation as a strategy to improve antibody-based therapeutics. Nat. Rev. Drug Discov. 8, 226-234. doi: 10.1038/nrd2804

Jiang, L. W., and Rogers, J. C. (1998). Integral membrane protein sorting to vacuoles in plant cells: evidence for two pathways. J. Cell Biol. 143, 1183-1199. doi: 10.1083/jcb.143.5.1183

Kajiura, H., Okamoto, T., Misaki, R., Matsuura, Y., and Fujiyama, K. (2012). Arabidopsis beta1,2-xylosyltransferase: substrate specificity and participation in the plant-specific $N$-glycosylation pathway. J. Biosci. Bioeng. 113, 48-54. doi: 10.1016/j.jbiosc.2011.09.011

Karg, S. R., Frey, A. D., and Kallio, P. T. (2010). Reduction of $N$-linked xylose and fucose by expression of rat beta1,4- $N$-acetylglucosaminyltransferase III in tobacco BY-2 cells depends on Golgi enzyme localization domain and genetic elements used for expression. J. Biotechnol. 146, 54-65. doi: 10.1016/j.jbiotec.2010.01.005

Koprivova, A., Stemmer, C., Altmann, F., Hoffmann, A., Kopriva, S., Gorr, G., et al. (2004). Targeted knockouts of Physcomitrella lacking plant-specific immunogenic N-glycans. Plant Biotechnol. J. 2, 517-523. doi: 10.1111/j.1467-7652.2004.00100.x Li, H., Sethuraman, N., Stadheim, T. A., Zha, D., Prinz, B., Ballew, N., et al. (2006). Optimization of humanized IgGs in glycoengineered Pichia pastoris. Nat. Biotechnol. 24, 210-215. doi: 10.1038/nbt1178

Liebminger, E., Veit, C., Pabst, M., Batoux, M., Zipfel, C., Altmann, F., et al. (2011). Beta- $N$-acetylhexosaminidases HEXO1 and HEXO3 are responsible for the formation of paucimannosidic N-glycans in Arabidopsis thaliana. J. Biol. Chem. 286, 10793-10802. doi: 10.1074/jbc.M110.178020

Loos, A., and Steinkellner, H. (2012). IgG-Fc glycoengineering in nonmammalian expression hosts. Arch. Biochem. Biophys. 526, 167-173. doi: 10.1016/j.abb.2012.05.011

Lozano-Juste, J., and Cutler, S. R. (2014). Plant genome engineering in full bloom. Trends Plant Sci. 19, 284-287. doi: 10.1016/j.tplants.2014.02.014

Matsuo, K., and Matsumura, T. (2011). Deletion of fucose residues in plant $N$ glycans by repression of the GDP-mannose 4,6-dehydratase gene using virusinduced gene silencing and RNA interference. Plant Biotechnol. J. 9, 264-281. doi: 10.1111/j.1467-7652.2010.00553.x

Meuris, L., Santens, F., Elson, G., Festjens, N., Boone, M., Dos Santos, A., et al. (2014). GlycoDelete engineering of mammalian cells simplifies $N$-glycosylation of recombinant proteins. Nat. Biotechnol. 32, 485-489. doi: 10.1038/nbt.2885

Nagels, B., Van Damme, E. J., Callewaert, N., and Weterings, K. (2012a). Introduction of tri-antennary N-glycans in Arabidopsis thaliana plants. Plant Sci. 185-186, 161-168. doi: 10.1016/j.plantsci.2011.10.002

Nagels, B., Van Damme, E. J., Callewaert, N., Zabeau, L., Tavernier, J., Delanghe, J. R., et al. (2012b). Biologically active, magnICON $\left({ }^{\circledR}\right)$-expressed EPO-Fc from stably transformed Nicotiana benthamiana plants presenting tetra-antennary $N$-glycan structures. J. Biotechnol. 160, 242-250. doi: 10.1016/j.jbiotec.2012.03.003

Nagels, B., Van Damme, E. J., Pabst, M., Callewaert, N., and Weterings, K. (2011). Production of complex multiantennary $N$-glycans in Nicotiana benthamiana plants. Plant Physiol. 155, 1103-1112. doi: 10.1104/pp.110.168773

Narasimhan, S. (1982). Control of glycoprotein synthesis. UDP-GlcNAc:glycopeptide beta $4-N$-acetylglucosaminyltransferase III, an enzyme in hen oviduct which adds GlcNAc in beta 1-4 linkage to the beta-linked mannose of the trimannosyl core of N-glycosyl oligosaccharides. J. Biol. Chem. 257, 10235-10242.

Ohtsubo, K., and Marth, J. D. (2006). Glycosylation in cellular mechanisms of health and disease. Cell 126, 855-867. doi: 10.1016/j.cell.2006.08.019

Oikawa, A., Lund, C. H., Sakuragi, Y., and Scheller, H. V. (2013). Golgi-localized enzyme complexes for plant cell wall biosynthesis. Trends Plant Sci. 18, 49-58. doi: 10.1016/j.tplants.2012.07.002

Pagny, S., Bouissonnie, F., Sarkar, M., Follet-Gueye, M. L., Driouich, A., Schachter, H., et al. (2003). Structural requirements for Arabidopsis beta1,2xylosyltransferase activity and targeting to the Golgi. Plant J. 33, 189-203. doi: 10.1046/j.0960-7412.2002.01604.x

Palacpac, N. Q., Yoshida, S., Sakai, H., Kimura, Y., Fujiyama, K., Yoshida, T., et al. (1999). Stable expression of human beta1,4-galactosyltransferase in plant cells modifies $N$-linked glycosylation patterns. Proc. Natl. Acad. Sci. U.S.A. 96, 46924697. doi: 10.1073/pnas.96.8.4692

Pandhal, J., and Wright, P. C. (2010). N-Linked glycoengineering for human therapeutic proteins in bacteria. Biotechnol. Lett. 32, 1189-1198. doi: 10.1007/s10529010-0289-6

Parsons, J., Altmann, F., Arrenberg, C. K., Koprivova, A., Beike, A. K., Stemmer, C., et al. (2012). Moss-based production of asialo-erythropoietin devoid of Lewis 
A and other plant-typical carbohydrate determinants. Plant Biotechnol. J. 10, 851-861. doi: 10.1111/j.1467-7652.2012.00704.x

Ratner, M. (2014). Genentech's glyco-engineered antibody to succeed Rituxan. Nat. Biotechnol. 32, 6-7. doi: 10.1038/nbt0114-6b

Rivera, A. M., Strauss, K. W., Van Zundert, A., and Mortier, E. (2005). The history of peripheral intravenous catheters: how little plastic tubes revolutionized medicine. Acta Anaesthesiol. Belg. 56, 271-282.

Roth, J., Zuber, C., Park, S., Jang, I., Lee, Y., Kysela, K. G., et al. (2010). Protein $\mathrm{N}$-glycosylation, protein folding, and protein quality control. Mol. Cells 30, 497506. doi: 10.1007/s10059-010-0159-z

Rouwendal, G. J., Wuhrer, M., Florack, D. E., Koeleman, C. A., Deelder, A M., Bakker, H., etal. (2007). Efficient introduction of a bisecting GlcNAc residue in tobacco $\mathrm{N}$-glycans by expression of the gene encoding human $N$-acetylglucosaminyltransferase III. Glycobiology 17, 334-344. doi: 10.1093/gly$\mathrm{cob} / \mathrm{cwl} 078$

Saint-Jore-Dupas, C., Nebenfuhr, A., Boulaflous, A., Follet-Gueye, M. L., Plasson, C., Hawes, C., et al. (2006). Plant $N$-glycan processing enzymes employ differen targeting mechanisms for their spatial arrangement along the secretory pathway. Plant Cell 18, 3182-3200. doi: 10.1105/tpc.105.036400

Sarrion-Perdigones, A., Vazquez-Vilar, M., Palaci, J., Castelijns, B., Forment, J., Ziarsolo, P., et al. (2013). GoldenBraid 2.0: a comprehensive DNA assembly framework for plant synthetic biology. Plant Physiol. 162, 1618-1631. doi: $10.1104 /$ pp.113.217661

Schähs, M., Strasser, R., Stadlmann, J., Kunert, R., Rademacher, T., and Steinkellner, H. (2007). Production of a monoclonal antibody in plants with a humanized $N$-glycosylation pattern. Plant Biotechnol. J. 5, 657-663. doi: 10.1111/j.14677652.2007.00273.x

Schneider, J. D., Marillonnet, S., Castilho, A., Gruber, C., Werner, S., Mach, L., et al. (2014). Oligomerization status influences subcellular deposition and glycosylation of recombinant butyrylcholinesterase in Nicotiana benthamiana. Plant Biotechnol. J. 12, 832-839. doi: 10.1111/pbi.12184

Schoberer, J., Liebminger, E., Botchway, S. W., Strasser, R., and Hawes, C. (2013). Time-resolved fluorescence imaging reveals differential interactions of $\mathrm{N}$-glycan processing enzymes across the Golgi stack in planta. Plant Physiol. 161, 17371754. doi: $10.1104 /$ pp.112.210757

Schoberer, J., Runions, J., Steinkellner, H., Strasser, R., Hawes, C., and Osterrieder, A. (2010). Sequential depletion and acquisition of proteins during Golgi stack disassembly and reformation. Traffic 11, 1429-1444. doi: 10.1111/j.16000854.2010.01106.x

Schoberer, J., and Strasser, R. (2011). Sub-compartmental organization of Golgiresident $\mathrm{N}$-glycan processing enzymes in plants. Mol. Plant 4, 220-228. doi: $10.1093 / \mathrm{mp} / \mathrm{ssq} 082$

Schoberer, J., Vavra, U., Stadlmann, J., Hawes, C., Mach, L., Steinkellner, H., et al. (2009). Arginine/lysine residues in the cytoplasmic tail promote ER export of plant glycosylation enzymes. Traffic 10, 101-115. doi: 10.1111/j.16000854.2008.00841.x

Schuster, M., Umana, P., Ferrara, C., Brünker, P., Gerdes, C., Waxenecker, G., et al. (2005). Improved effector functions of a therapeutic monoclonal lewis Y-specific antibody by glycoform engineering. Cancer Res. 65, 7934-7941.

Shin, Y. J., Chong, Y. J., Yang, M. S., and Kwon, T. H. (2011). Production of recombinant human granulocyte macrophage-colony stimulating factor in rice cell suspension culture with a human-like $\mathrm{N}$-glycan structure. Plant Biotechnol. J. 9, 1109-1119. doi: 10.1111/j.1467-7652.2011.00636.x

Shinkawa, T., Nakamura, K., Yamane, N., Shoji-Hosaka, E., Kanda, Y., Sakurada, M., et al. (2003). The absence of fucose but not the presence of galactose or bisecting $\mathrm{N}$-acetylglucosamine of human IgG1 complex-type oligosaccharides shows the critical role of enhancing antibody-dependent cellular cytotoxicity. J. Biol. Chem. 278, 3466-3473. doi: 10.1074/jbc.M210665200

Solá, R. J., and Griebenow, K. (2010). Glycosylation of therapeutic proteins: an effective strategy to optimize efficacy. BioDrugs 24, 9-21. doi: 10.2165/11530550000000000-00000

Sourrouille, C., Marquet-Blouin, E., D’Aoust, M. A., Kiefer-Meyer, M. C., Seveno, M., Pagny-Salehabadi, S., et al. (2008). Down-regulated expression of plant-specific glycoepitopes in alfalfa. Plant Biotechnol. J. 6, 702-721. doi: 10.1111/j.1467-7652.2008.00353.x

Staudacher, E., Dalik, T., Wawra, P., Altmann, F., and Marz, L. (1995). Functional purification and characterization of a GDP-fucose: beta- $N$-acetylglucosamine (Fuc to Asn linked GlcNAc) alpha 1,3-fucosyltransferase from mung beans. Glycoconj. J. 12, 780-786. doi: 10.1007/BF00731239
Stoger, E., Fischer, R., Moloney, M., and Ma, J. K. (2014). Plant molecular pharming for the treatment of chronic and infectious diseases. Annu. Rev. Plant Biol. 65, 743-768. doi: 10.1146/annurev-arplant-050213-0 35850

Strasser, R., Altmann, F., Glössl, J., and Steinkellner, H. (2004a). Unaltered complex $N$-glycan profiles in Nicotiana benthamiana despite drastic reduction of beta1,2- $N$-acetylglucosaminyltransferase I activity. Glycoconj. J. 21, 275-282. doi: 10.1023/B:GLYC.0000045099.29038.04

Strasser, R., Altmann, F., Mach, L., Glössl, J., and Steinkellner, H. (2004b). Generation of Arabidopsis thaliana plants with complex $N$-glycans lacking beta1,2-linked xylose and core alpha1,3-linked fucose. FEBS Lett. 561, 132-136. doi: 10.1016/S0014-5793(04)00150-4

Strasser, R., Bondili, J. S., Schoberer, J., Svoboda, B., Liebminger, E., Glossl, J., et al. (2007a). Enzymatic properties and subcellular localization of Arabidopsis beta- $N$-acetylhexosaminidases. Plant Physiol. 145, 5-16. doi: 10.1104/pp.107.1 01162

Strasser, R., Bondili, J. S., Vavra, U., Schoberer, J., Svoboda, B., Glossl, J., et al. (2007b). A unique beta1,3-galactosyltransferase is indispensable for the biosynthesis of $N$-glycans containing Lewis a structures in Arabidopsis thaliana. Plant Cell 19, 2278-2292. doi: 10.1105/tpc.107.052985

Strasser, R., Castilho, A., Stadlmann, J., Kunert, R., Quendler, H., Gattinger, P., et al. (2009). Improved virus neutralization by plant-produced anti-HIV antibodies with a homogeneous beta1,4-galactosylated $N$-glycan profile. J. Biol. Chem. 284, 20479-20485. doi: 10.1074/jbc.M109.014126

Strasser, R., Stadlmann, J., Schähs, M., Stiegler, G., Quendler, H., Mach, L., et al. (2008). Generation of glyco-engineered Nicotiana benthamiana for the production of monoclonal antibodies with a homogeneous human-like $\mathrm{N}$ glycan structure. Plant Biotechnol. J. 6, 392-402. doi: 10.1111/j.1467-7652.2008.0 0330. $\mathrm{x}$

Uliana, A. S., Giraudo, C. G., and Maccioni, H. J. (2006). Cytoplasmic tails of SialT2 and GalNAcT impose their respective proximal and distal Golgi localization. Traffic 7, 604-612. doi: 10.1111/j.1600-0854.2006.00413.x

Umana, P., Jean-Mairet, J., Moudry, R., Amstutz, H., and Bailey, J. E. (1999). Engineered glycoforms of an antineuroblastoma IgG1 with optimized antibodydependent cellular cytotoxic activity. Nat. Biotechnol. 17, 176-180. doi: $10.1038 / 6179$

van Dussen, L., Zimran, A., Akkerman, E. M., Aerts, J. M., Petakov, M., Elstein, D., et al. (2013). Taliglucerase alfa leads to favorable bone marrow responses in patients with type I Gaucher disease. Blood Cells Mol. Dis. 50, 206-211. doi: 10.1016/j.bcmd.2012.11.001

Varki, A. (1993). Biological roles of oligosaccharides: all of the theories are correct. Glycobiology 3, 97-130. doi: 10.1093/glycob/3.2.97

Varki, A. (2006). Nothing in glycobiology makes sense, except in the light of evolution. Cell 126, 841-845. doi: 10.1016/j.cell.2006.08.022

Vézina, L. P., Faye, L., Lerouge, P., D’Aoust, M. A., Marquet-Blouin, E., Burel, C., et al. (2009). Transient co-expression for fast and high-yield production of antibodies with human-like $\mathrm{N}$-glycans in plants. Plant Biotechnol. J. 7, 442-455. doi: 10.1111/j.1467-7652.2009.00414.x

Von Schaewen, A., Sturm, A., O'Neill, J., and Chrispeels, M. J. (1993). Isolation of a mutant Arabidopsis plant that lacks $N$-acetyl glucosaminyl transferase-I and is unable to synthesize golgi-modified complex $N$-linked glycans. Plant Physiol. 102, 1109-1118. doi: 10.1104/pp.102.4.1109

Walsh, G. (2010). Biopharmaceutical benchmarks 2010. Nat. Biotechnol. 28, 917924. doi: 10.1038/nbt0910-917

Weber, E., Gruetzner, R., Werner, S., Engler, C., and Marillonnet, S. (2011). Assembly of designer TAL effectors by Golden Gate cloning. PLoS ONE 6:e19722. doi: 10.1371/journal.pone.0019722

Wee, E. G., Sherrier, D. J., Prime, T. A., and Dupree, P. (1998). Targeting of active sialyltransferase to the plant Golgi apparatus. Plant Cell 10, 1759-1768. doi: 10.1105/tpc.10.10.1759

Wilson, I. B., Zeleny, R., Kolarich, D., Staudacher, E., Stroop, C. J., Kamerling, J. P., et al. (2001). Analysis of Asn-linked glycans from vegetable foodstuffs: widespread occurrence of Lewis a, core alpha1,3-linked fucose and xylose substitutions. Glycobiology 11, 261-274. doi: 10.1093/glycob/11.4.261

www.federalgrants.com. (2012). Butyrylcholinesterase Expression in Plants Federal Grant. Available at: http://www.federalgrants.com/ButyrylcholinesteraseExpression-in-Plants-33798.html [accessed July 7, 2014].

Yamane-Ohnuki, N., Kinoshita, S., Inoue-Urakubo, M., Kusunoki, M., Iida, S., Nakano, R., et al. (2004). Establishment of FUT8 knockout Chinese hamster ovary 
cells: an ideal host cell line for producing completely defucosylated antibodies with enhanced antibody-dependent cellular cytotoxicity. Biotechnol. Bioeng. 87, 614-622. doi: 10.1002/bit.20151

Zeitlin, L., Bohorov, O., Bohorova, N., Hiatt, A., Kim, D. H., Pauly, M. H., et al. (2013). Prophylactic and therapeutic testing of Nicotiana-derived RSVneutralizing human monoclonal antibodies in the cotton rat model. MAbs 5, 263-269. doi: 10.4161/mabs.23281

Zeitlin, L., Pettitt, J., Scully, C., Bohorova, N., Kim, D., Pauly, M., et al. (2011). Enhanced potency of a fucose-free monoclonal antibody being developed as an Ebola virus immunoprotectant. Proc. Natl. Acad. Sci. U.S.A. 108, 20690-20694. doi: 10.1073/pnas.1108360108

Zimran, A., Brill-Almon, E., Chertkoff, R., Petakov, M., Blanco-Favela, F., Munoz, E. T., etal. (2011). Pivotal trial with plant cell-expressed recombinant glucocerebrosidase, taliglucerase alfa, a novel enzyme replacement therapy for Gaucher disease. Blood 118, 5767-5773. doi: 10.1182/blood-2011-07-3 66955
Conflict of Interest Statement: The authors declare that the research was conducted in the absence of any commercial or financial relationships that could be construed as a potential conflict of interest.

Received: 10 July 2014; accepted: 16 September 2014; published online: 08 October 2014.

Citation: Loos A and Steinkellner H (2014) Plant glyco-biotechnology on the way to synthetic biology. Front. Plant Sci. 5:523. doi: 10.3389/fpls.2014.00523

This article was submitted to Plant Physiology, a section of the journal Frontiers in Plant Science.

Copyright (C) 2014 Loos and Steinkellner. This is an open-access article distributed under the terms of the Creative Commons Attribution License (CC BY). The use, distribution or reproduction in other forums is permitted, provided the original author(s) or licensor are credited and that the original publication in this journal is cited, in accordance with accepted academic practice. No use, distribution or reproduction is permitted which does not comply with these terms. 